Theories \& Applications, the International Edition

Printed Version: (ISSN 2090-5262)

Online Version: (ISSN 2090-5270)

March 2012, Volume 2, No. 1 Pages (94 - 101)

\title{
The Effect of Jump Ropes Exercise on Some Physical and Physiological Variables in Physical Education Students
}

\author{
Marwan Ali Mohamed Shamakh*
}

\begin{abstract}
:
Jump rope exercises are considered an important type of exercises in the development of physical and physiological capabilities, such as, muscular endurance, cardio-respiratory endurance, agility, coordination, balance, and the efficiency of the Circulatory and respiratory systems The purpose of this study was to to develop some physical and physiological capacities to raise the level of physical efficiency.The study was conducted on a sample of 40 students from the Faculty of Physical Education for men, applied to the proposed training program in a 10-week, 3 units per week. there were differences in the results of physical measurements between the pre-and post measurements; for example, leg muscles strength improved by 5.46\% (pre, $206.04 \pm 12.65$-post217.3 \pm 14.46 ) There are also differences in the physiological measurements between the pre- and post measurements; for example, the resting heart rate improved by $11.24 \%$ (pre, $77.4 \pm 4.24$ post,68.7 $+4.62 \mathrm{beat} / \mathrm{min}$ ).
\end{abstract}

\section{Introduction:}

$\mathrm{P}$ racticing in physical exercise is the main issue to keep a proper health state and an acceptable physical and physiological fitness for all ages and both sexes.

Regular exercises will develop physical and physiological fitness in addition to decreasing the health risks.

Miu's (2009) confirmed the role of physical aerobic exercises on enhancing the physical \& cognitive abilities even for the elder people.

Mohamed Shehata et al (1992), Khairya ElSokary \& Mohamed Abd El-Halim (1997) stated that physical exercises works on developing flexibility, strength and elasticity of ligaments, also it helps in increasing the range of motion and decreasing the risk of injury in addition to developing the neuromuscular coordination and adjusting the muscle tone and strength. In addition to developing the functional efficiency of the circulatory and respiratory system, lowering cholesterol and stored fats level, increasing metabolism rates

*Lecturer, Department of Exercise and Gymnastics Training, Faculty of Physical Education, Alexandria University, Egypt. besides improving the level of joints conditioning.

Best \& Taylor (1970) pointed out that practicing exercise regularly leads to decreasing heart rate during rest because of the effect of exercise on increasing the heart muscle volume and muscle adduction ability and the response of vagus nerve that helps in slowing the heart rate.

Johnson and Buskirk (1974) stated that physical exercises leads to increasing the heart efficiency and helps the heart muscle in supplying the muscles with more blood which will enable the individual to get his whole need of oxygen during exercise that will enable him to reach his peak performance.

Acevedo (2006) and Stienhaus et al (1988) confirmed that physical exercises affect the cardio-respiratory fitness positively which is considered a main fitness component and a highly demanded functional efficiency.

Astrand and Rahalk (1977) added that heart rate is a main physiological indicator that can be used to monitor the effect of exercises training and helps in directing training programs.

Devries (1976) pointed out to the possibility of using heart rate to determine the time of 
returning back to the normal state after physical effort.

Cheng et al (2003) and Ahmed Khater (1979) also confirmed that the VO2 max test can be used for monitoring fitness levels as $\mathrm{VO} 2 \mathrm{max}$ is directly proportional to fitness levels.

Jumping ropes exercises is considered an important type of exercise used to develop the physical and physiological abilities; such as muscular power, strength, range of motion, muscular endurance, cardio respiratory endurance, agility, balance, neuromuscular coordination, leg and arm joints flexibility and cardio respiratory fitness.

Sharkey (1990) confirms that rope exercises needs a high level of coordination when moving more than one part of the body in the same time and in several directions in addition to acquiring other fitness elements like agility, flexibility, speed, accuracy and motion sensation. Also it needs a type of dynamic balance that corporate all the body muscles to keep this state of balance during performance where a variation of jumps, rotations, swings and skills are used without stops which reflects a high level of physical efficiency for the individual.

Quirk and Sinning (1982) stated that the value of rope exercises lie in its simplicity as a wy to develop the physical efficiency and capacity for individuals who do not have much time to practice a regular sports activity. Also rope exercises help in developing Vo2max.

Baker (1969) stated that rope exercises matches with running exercises where both of them develop the efficiency of the cardio respiratory system.

\section{Research aim:}

The research aims for identifying the effect of rope exercises training program on physical abilities and some physiological variables for students in the faculty of sports education.

\section{Research hypothesis:}

1. Interval circular rope exercise training has a positive effect on developing some physical abilities
2. Interval circular rope exercise training has a positive effect on developing some physiological variables.

\section{Research procedures:}

\section{Research method:}

The experimental method was used using pre and post measurements on one experimental group.

\section{Research sample:}

40 physical education students have consented to participated in this study.mean age 20.65 years +1.34 and mean height $178.68 \mathrm{~cm}+5.37$ and mean weight $73.82 \mathrm{~kg}+9.10$.

\section{Research tools:}

The researcher used the following measurements:

Anthropometric measurements including:

- Height: the total height of the body was measured by the restameter to the nearest $1 / 2$ $\mathrm{cm}$

- Weight: using the medical scale to the nearest $1 / 2 \mathrm{~kg}$

\section{Physical measurements:}

- Standing broad jump test to measure the legs' muscular power

- Sit-ups test in 30 seconds to measure the speed strength for Abdominal muscles

- Push-ups test till fatigue to measure arms' muscles strength

- Purpee test till fatigue to measure muscular endurance

- Sit-ups test to measure abdominal muscles endurance

- Purpee test in $10 \mathrm{sec}$ to measure agility

- Running in figure 8 to measure co-ordination

- Measuring flexibility through trunk flexion

- Sprint $50 \mathrm{~m}$ to the nearest $1 / 100 \mathrm{sec}$ to measure speed

These measurements where chosen based on previous researches and based on the proven reliability and suitability though statistical analysis according to what was mentioned by Mohamed Alawai \& Mohamed Nasr (2000) and Sobhy Hassanin (2001). 


\section{Physiological variables:}

- Measuring heart rate (H.R) during rest

- Measuring heart rate(H.R) after physical effort

- Harvard step test to measure physical efficiency

- Sargant test

- Vital Capacity (V.C) test

- Relative Vital Capacity (V.C) test

- Holding breath time test

\section{Training program}

The student have gone through two weeks educational program for the selected rope exercise before training.

The researcher used the interval circular training for 10 weeks "3 sessions per week, 60 min each", same schedule was applied by Claus Heberstrelt (1982).

Preliminary part: warm-up for preparing and adapting the body for the coming physical load (5 min)

Main part: which includes the jumping rope exercises program using the interval circular training method (50 min)

Final part: which includes some swings and relaxation exercises for cool down and returning to the normal state.

\section{Determining the proper training dose:}

The researcher performed the peak performancetest before applying the interval circular training method at the beginning of each training period where the gradual increase of training load was noted starting from the intermediate load according to the peak intensity for each individual starting with one training circle then two and finally three considering the scientific basis for training and the proper recovery and rest times for each session according to Mohamed H. Alawy (1997).

\section{Applying experiment:}

The pre measurements were taken for both of physical and physiological variables, then the recommended training program was applied for 8 weeks where the post measurements were taken afterwards.

\section{Statistical processing:}

The following statistical processing methods were used:

- Arithmetic mean

- Standard deviation

- T test

- Percentage ratio 
Results \& discussions:

\section{Results:}

Table (1)

Statistical significance for pre and post measurements for the physical variables

\begin{tabular}{|c|c|c|c|c|c|c|c|}
\hline \multirow{2}{*}{$\begin{array}{l}\text { Statistical } \\
\text { processing }\end{array}$} & \multicolumn{2}{|c|}{ Pre measurement } & \multicolumn{2}{|c|}{$\begin{array}{c}\text { Post } \\
\text { measurement }\end{array}$} & \multirow{2}{*}{$\begin{array}{l}\text { Difference } \\
\text { between } 2 \\
\text { means }\end{array}$} & \multirow{2}{*}{ T value } & \multirow{2}{*}{$\begin{array}{c}\text { Progress } \\
\text { percentage }\end{array}$} \\
\hline & $\mathbf{M}$ & SD & $\mathbf{M}$ & SD & & & \\
\hline Standing broad jump & 206.04 & 12.65 & 217.3 & 14.46 & 11.26 & $7.42 *$ & $\% 5.46$ \\
\hline Sit-ups in $30 \mathrm{sec}$ & 22.4 & 2.14 & 26.7 & 2.85 & 4.3 & $13.24 *$ & $\% 19.24$ \\
\hline Push-ups till fatigue & 24.35 & 4.78 & 34.75 & 6.87 & 10.4 & $11.85^{*}$ & $\% 42.70$ \\
\hline Purpee till fatigue & 27.34 & 1.79 & 35.55 & 2.57 & 8.12 & $16.37 *$ & $\% 29.70$ \\
\hline Sit-ups test & 34.63 & 3.53 & 45.37 & 3.24 & 10.74 & $11.57 *$ & $\% 31.01$ \\
\hline Purpee in 10 sec & 6.24 & 0.73 & 7.68 & 0.64 & 1.44 & $16.47^{*}$ & $\% 23.07$ \\
\hline Running in figure 8 & 19.64 & 1.92 & 16.91 & 1.34 & 2.73 & $8.76^{*}$ & $\% 13.90$ \\
\hline Trunk flexion & 50.48 & 2.71 & 55.31 & 7.43 & 4.83 & $7.21 *$ & $\% 9.62$ \\
\hline Sprint 50 m & 7.32 & 0.34 & 6.46 & 0.39 & 0.86 & $18.86^{*}$ & $\% 11.74$ \\
\hline
\end{tabular}

Figure (1)

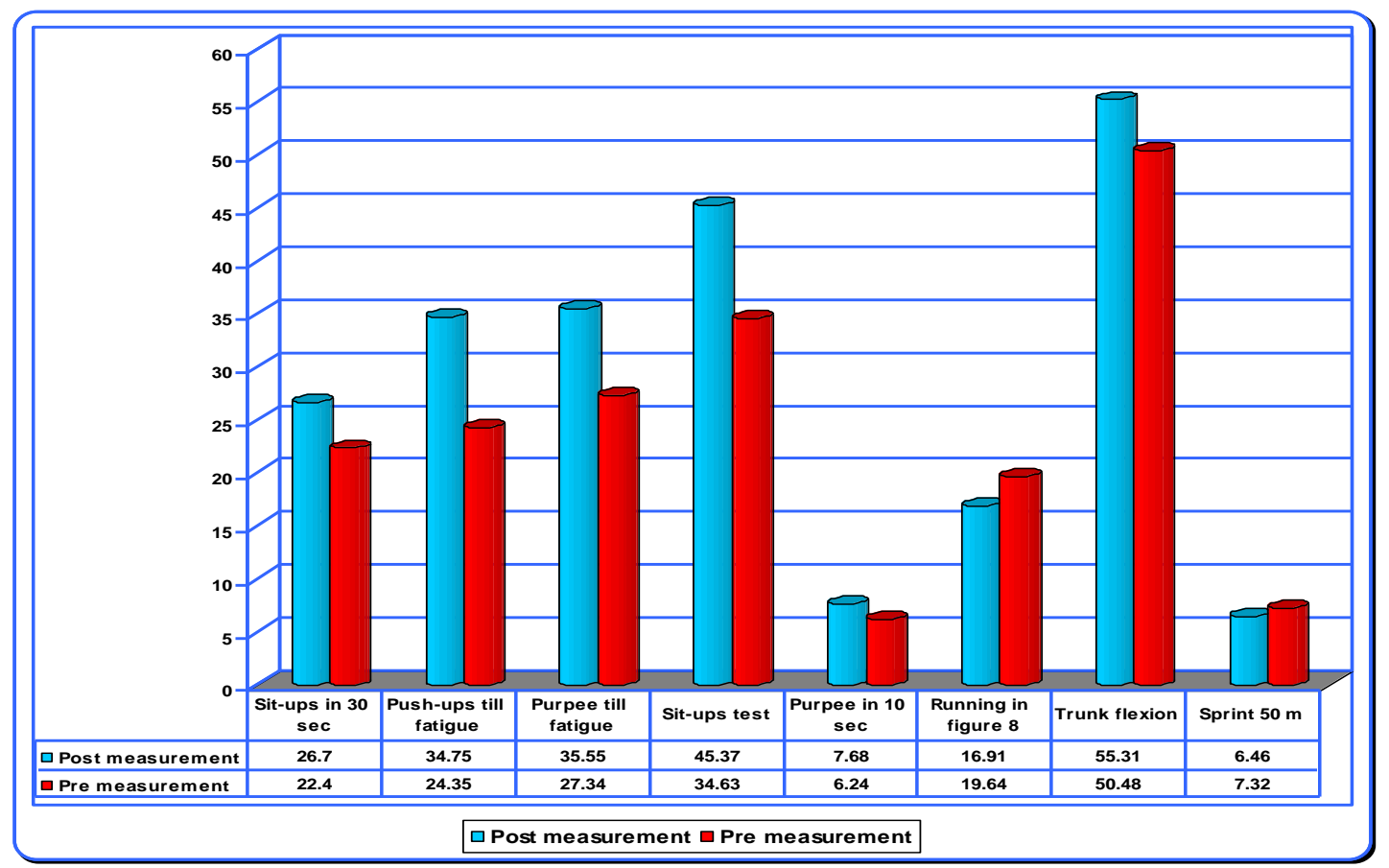

Figure (1)A graphical representation for statistical significance for pre and post measurements for the physical variables

Table (1) and Fig (1) shows the presence of significant statistical differences between the pre and post measurements in favor of the post measurement for the physical variables testing that were used in this research to evaluate the physical variables for the research sample
Where value of $\mathrm{T}$ was between 7.21 and 18.86 which was higher than the value of $\mathrm{T}$ at 0.05 and this development is referred to the contents of the recommended training program that was applied on the research sample. 
Table (2)

Statistical significance for pre and post measurements forthe physiological variables

\begin{tabular}{|c|c|c|c|c|c|c|c|}
\hline \multirow{2}{*}{$\begin{array}{l}\begin{array}{l}\text { Statistical } \\
\text { processing }\end{array} \\
\text { Physiołogical } \\
\text { tests }\end{array}$} & \multicolumn{2}{|c|}{ Pre measurement } & \multicolumn{2}{|c|}{ Post measurement } & \multirow{2}{*}{$\begin{array}{c}\text { Difference } \\
\text { between } 2 \\
\text { means }\end{array}$} & \multirow[b]{2}{*}{ T value } & \multirow{2}{*}{$\begin{array}{c}\text { Progress } \\
\text { percentage }\end{array}$} \\
\hline & $\mathbf{M}$ & SD & $\mathbf{M}$ & SD & & & \\
\hline H.R during rest & 77.4 & 4.24 & 68.7 & 4.62 & 8.7 & $26.54 *$ & $\% \quad 11.24$ \\
\hline H.R After physical effort & 189.21 & 6.53 & 174.2 & 8.36 & 15.01 & $21.81 *$ & $\% 7.93$ \\
\hline Harvard step test & 81.53 & 2.47 & 85.24 & 5.32 & 3.71 & $12.24 *$ & $\% 4.55$ \\
\hline V.C & 3880.47 & 42.93 & 4248.75 & 90.19 & 368.28 & $26.87^{*}$ & $\% 9.49$ \\
\hline Relative V.C & 58.90 & 0.52 & 64.84 & 1.32 & 5.94 & $29.80^{*}$ & $\% 10.08$ \\
\hline Sargant test & 84.45 & 0.54 & 92.59 & 1.10 & 8.14 & $42.35^{*}$ & $\% 9.64$ \\
\hline Holding breath time & 68.91 & 1.00 & 79.34 & 2.25 & 10.43 & $28.38 *$ & $\% 15.14$ \\
\hline
\end{tabular}

Figure (2

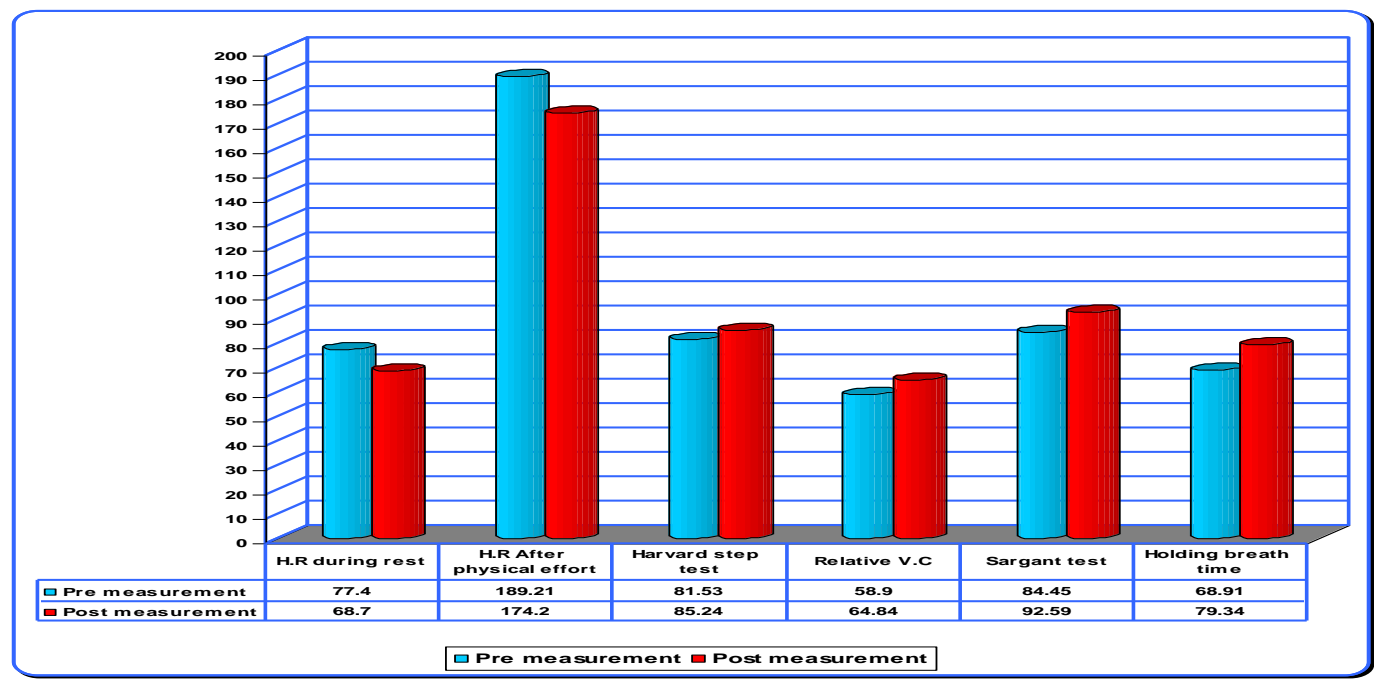

Figure (2)A graphical representation for the statistical significance for pre and post measurements for the physiological variables

Table (2) and Fig (2) shows the presence of significant statistical differences between the pre and post measurements in favor of the post measurement for the physiological variables testing that were used in this research to evaluate the physical variables for the research sample. Where value of $\mathrm{T}$ was between 12.24 and 42.35 which was higher than the value of $T$ at 0.05 and this development is referred to the contents of the recommended training program that was applied on the research sample.

\section{Results Discussions:}

The results of this research prove that the recommended training program had a positive effect on the following variables:
From table (1) and figure (1) we can see the presence of significant statistical differences between the pre and post measurements for the physical variables testing in favor of the post measurement at $\mathrm{T}=0.05$

This is referred to the progress in the physical variables testing due to the positive effect of the recommended training program of jumping ropes exercises using interval circular training method which worked well on developing the physical abilities of the research sample.

These results matched with Farida Osman and Mohamed Osman's research (1987) which proved the significant progress in physical abilities due to applying the recommended training program. 
Also it matches with what was mentioned by Faten El-Batal (1993) that using the hand tools in exercises develops the neuromuscular coordination and works on promoting the rhythm and synchronization of movements.

Kwon \& Hwang (2007) and Kariman Ismail (1993) also confirmed that jumping rope exercise can develop physical abilities more than free exercises.

Barteck (1999) also pointed out that exercise training programs aims mainly for developing the level of cardio respiratory system performance accompanied with developing movement abilities as coordination, power and speed.

The results of this research also matches with Moritani's results (1999) which stated that physical training programs that include exercises aiming for enhancing the level of physical fitness and movement abilities helps in the progress of the physical testing results which is mainly known as "transition of the positive effect of training".

Gamal Shaker \& Hashem Adnan (2008) also mentioned that the applied physical training programs applied on the research sample had a positive effect on fitness components that are related to health and body composition.

in table (2) and figure (2) there are significant statistical differences between the pre and post measurements for the physiological variables testing in favor of the post measurement at $\mathrm{T}=$ 0.05 .

This is referred to the progress in the physiological variables testing due to the positive effect of the recommended training program of jumping ropes exercises using interval circular training method which worked well on developing the physiological variables of the research sample.

These results matches with Zarins et al (2009) which stated that aerobic training programs have positive effects on VO2max.

Farida Osman \& Mohamed Osman (1987) also proved that physical training programs helped in decreasing the heart rate during rest.

Debra \& Douglas (1991) stated that there are positive results for the physiological responses of the body internal organs due to using aerobic training programs for 15:30 min daily.

Sharkey (1997) also confirmed that physical training leads to changing in lungs capacity and size.

The results also matched with Jackson et al (1999) and Martin \& Coe (1997) who reported the positive effects of regular exercises lies in developing the functional aerobic abilities and developing the function of lungs in addition to promoting the levels of endurance, strength, agility \& flexibility.

Frank (2001) pointed out that practicing in aerobic exercises lead to positive changes in the mechanism \& function of breathing as they increase the efficiency of functional performance for lungs and the depth and volume of respiration as well as the efficiency of respiration muscles and cardio respiratory system.

Suzan Hanafy (2003) also mentioned that exercises training had a positive effect on developing physiological responses as heart rate and the efficiency of the cardio respiratory system which is reflected generally on the individual's general health status.

\section{Conclusions:}

1. There were significant differences between pre and post measurement in favor of post measurement for the physical abilities as power, strength, endurance \& coordination.

2. There were significant differences between pre and post measurement in favor on post measurement for the physiological variables as heart rate, Vital Capacity, physical efficiency and holding breath time.

\section{References:}

1. Acevedo EO, Webb HE, Weldy ML, Fabianke EC, Orndorff GR, Starks MA: Cardiorespiratory responses of Hi Fit and Low Fit subjects to mental challenge during exercise. Int J Sports Med. 2006 Dec;27(12):1013-22. Epub Apr 11. 2006

2. Ahmed, M. Khater : Game and training in football, Dar El- Maaref, Cairo 1979 
3. Astrand, P.O \& Rahahalk: Text Book of Work Physiology, 2nd ed.,Mcgrow Hill Book, Ca. N.R., 1977.

4. Baker,J.A., : Comparison of Rope Skipping and Jogging as methods of improving cardiovascular efficiency of college men, Research Quarterly, 39,1969.

5. Barteck o., : All around fitness, Konemann, Germany 1999 .

6. Best,N.B.\&Taylor,: “The Human Body,It's Anatomy and Physiology "Fourth, Champman , Hall,Itd,London, 354, 1970.

7. Cheng Y. J., Macera C. A., Addy C. L., Sy F. S. , Wieland D., Blair S. N.: Effects of physical activity on exercise tests and respiratory function. British Journal of Sports Medicine;37:521-528. 2003

8. Claus Hebestrelt : Planning analyzing and organizing the training Process, Edltor Harra Dletrich, Peinclples of Spots Training Sportvorlage Berlin, 1982.

9. Debra,T.and Douglas, L.: Physiological reaponses during aerobic dance of individuals grouped by aerobic capacity and dance experience research guartery for exercise and sports Vol.68, No 1,1991.

10. Devries,H.A.,: Physiology to Exercise for Physical Education and Atheltics,2nd ed .,W.M.C., Bloun CO., 1976.

11. Doris KY Miu: The Effect of Exercise Training in Term of Aerobic Exercise for 3 Months, on the Physical, Cognitive and Affective Function in Dementia Subjects, Department of Medicine and Geriatrics, Kwong Wah Hospital, 2009

12. Farida Osman and Mohamed Osman: The effect of a legalized training program for middle aged women on some anthropometric and physiological variables and fitness components, 1st sports congress, the faculty of sports education - AmmanUniversity - Jordan 1987.

13. Faten El-Batal : The effect of a recommended program using ropes on developing the neuromuscular coordination and the level of movement performance for rhythmic gymnastics juniors. The faculty of sports education - helwan university, 1993
14. Frank, J.Creny, \& Herold, W. Burton : Exercise Physiology for Health care professionals, First ed. Human Kinetics .New York . 2001.

15. Gamal Shaker \& Hashem Adnan : Water training with special tools for developing the health related fitness levels, the international sports scientific congress, El-Zarkaa, Jordan, 2008

16. Jackson, et al., : Physical activity for Health and fitness, Human Kinetics, Champaign I1. 1999.

17. Johnson,W.R.\& Buskrik,E.R., : "Science and Medicine of Exercise and Sports". 2nd.Ed,Herper Row (Publishers),New York,Evanston Fransis Co., London, p. 279, 1974.

18. Kariman Ismail : The effect of using free exercises and tools exercises on developing the level of some physical characteristics for kindergarten kids, The faculty of sports education, Alexandria university, 1993

19. Khairya El-Sokary \& Mohamed Abd ElHalim : Running physiology for long distance runners, Dar El-Maaref, part 1, 1997

20. Kwon MS, Hwang KS.: Effects of an exercise program on body composition, cardiopulmonary function, and physical fitness for obese children. Taehan Kanho Hakhoe Chi. Jun;37(4):568-75. 2007

21. Marten D.E. \& Coe. P.N. : Better Training for distance runners, 2nd., Human Kinetics, 1997 .

22. Mohamed Shehata et al : The basics of physical exercise, 1st edition, Monshaat ElMaaref, Alexandria, 1992

23. Mohamed, S . Hassanin: Measurement and assessment in physical education and sports, part 1, 4th edition, Dar El-Fekr El-Araby, Cairo, 2001

24. Mohamed,H,Alawy: Sports training science, 6th edition, Dar El-Maaref, Cairo, 1997.

25. Mohamed,H,Alawy \& Mohamed Nasr eldin, Radwan: Measurement in physical education and sports psychology, 2nd edition, Dar El-Fekr El-Araby, Cairo, 2000 
26. Moratani, T.,: Time Course of adaptation during Strength and power in sport, Blackwell Scientific publishers, London, 1999.

27. Quirk JE, Sinning WE: Anaerobic and aerobic responses of males and females to rope skipping. Med Sci Sports Exerc.;14(1):26-9. 1982

28. Sharkey B.J. : Physiology of Fitness, 3rd.ed., Human Kinetics Books ,U.S.A., 1990.

29. Sharkey B.J.: Fitness for sport. In Successful coaching, publication for the American sport education program, 2nd, ed., Human Kinetics 1997.

30. Steinhaus L. A., Dustman R. E., Ruhling R. 0., Emmerson R. Y., Johnson S. C., Shearer D.
E., Shigekatt J. W. and Bonekat W. H.: Cardiorespiratory fitness of young and older active and sedentary men, Brit.J.Sports Med. - Vol. 22, No.4, December, pp. 163-166.1988

31. Suzan M. Hanafy: Physical and psychological responses resulting from aerobic and anaerobic exercises for middle aged women, The faculty of sports education for men, Alexandria university, 2003.

32. Zarins ZA, WallisGA, Faghihnia N, Johnson ML, Fattor JA, Horning MA, Brooks GA: Effects of endurance training on cardio respiratory fitness and substrate partitioning in postmenopausal women. Metabolism. 2009. 